\section{Introduction to Guest Editor}

\section{Judith L. Trudel, M.D.}

David E. Beck, M.D. ${ }^{1,2}$

${ }^{1}$ Department of Colon and Rectal Surgery, Ochsner Clinic Foundation, New Orleans, Louisiana

${ }^{2}$ Ochsner Clinical School, University of Queensland, Brisbane, Australia

Clin Colon Rectal Surg 2012;25:123-124.

Dr.Judith L. Trudel is a clinical professor in the Division of Colon and Rectal Surgery, Department of Surgery, University of Minnesota, Minneapolis, where she is the program director for the colon and rectal surgery residency program. She practices colon and rectal surgery in St. Paul, Minnesota. Judith was born in Montréal, Canada and received her undergraduate and medical school training at Laval University in Québec, Canada. Her general surgery residency was completed at McGill University in Montréal; her colorectal surgery training at the Cleveland Clinic in Cleveland, Ohio. In addition, her academic formation includes several years of basic and clinical research, a Master of Science degree in experimental surgery from McGill University and a Masters degree in health professions education from the University of Illinois in Chicago.

Following her colorectal surgery training, Dr. Trudel joined the faculty at McGill University and had a busy educational and clinical colorectal practice. She moved to Minnesota in 2002 and maintains citizenship in both Canada and the United States.

Dr. Trudel is recognized as a national leader in surgical education. She has been involved in educating medical students and general surgery or colorectal residents for her entire professional career. As program director, she mentors trainees and junior faculty on a daily basis, and is involved in curriculum development and educational research. Her publications include eight book chapters and 42 peer-reviewed articles, and she is a reviewer for numerous prestigious journals. She actively participates in forums and committees on a national level to improve our knowledge and ability to educate trainees. In addition to these activities, Dr. Trudel maintains a busy colorectal surgery practice.

Dr. Trudel is a fellow of the Royal College of Physicians and Surgeons of Canada, of the American College of Surgeons, of the American Society of Colon and Rectal Surgeons (ASCRS), and the Society of Surgical Oncology. She is board certified in general surgery and colon and rectal surgery and is also listed in Best Doctors in America. She is the immediate past vicepresident of the ASCRS, serves actively on national society committees, and is a member of several Canadian and American specialty societies. She is a board member of the American Board of Colon and Rectal Surgery.

Judith and her husband, François Bédard, Ph.D., live in Woodbury, Minnesota. She has two children: Vincent, a freshman studying hospitality management at the University of Central Florida, Orlando; and Nicolas, a junior in high school. When not working, she enjoys keeping fit, spending time with friends and family, dragon boat racing, and cooking; she and François climbed Mount Kilimanjaro in July 2011.

On behalf of the readers of Clinics in Colon and Rectal Surgery, the Editorial Board thanks Dr. Trudel for serving as Guest Editor and for providing an important issue on surgical education.

\footnotetext{
Address for correspondence and Issue Theme Surgical Education reprint requests David $\mathrm{E}$. Beck, M.D., Department of Colon and Rectal Surgery, Ochsner Clinic Foundation, 1514 Jefferson Hwy., New Orleans, LA 70121 (e-mail: dbeckmd@aol.com).
} Publishers, Inc., 333 Seventh Avenue, New York, NY 10001, USA. Tel: +1(212) 584-4662.
DOI http://dx.doi.org/ $10.1055 / \mathrm{s}-0032-1322523$. ISSN 1531-0043. 